DOI 10.37882/2223-2982.2021.03.40

\title{
ОСОБЕННОСТИ ВЫПОЛНЕНИЯ СВИНГА ГОЛЬФИСТАМИ НА ЭТАПЕ НАЧАЛЬНОЙ ПОДГОТОВКИ
}

\section{FEATURES OF SWING PERFORMANCE BY GOLFERS AT THE INITIAL TRAINING STAGE}

N. Yakovleva

B. Yakovlev

Summary: The purpose of the work: to determine the features of the technique of full swing by golfers at the stage of initial training. The Swing Talk sensor was used to determine the kinematic characteristics of the swing. The trajectory of the club head, its position during contact with the ball, and the position of the club during contact with the ball were determined. The experiment involved 12 novice golfers aged 8 to 11 years. The full swing was performed with the iron No. 8 stick. The features of performing full swing depending on the age and duration of training of novice golfers are revealed.

Keywords: swing, swing kinematics, club head speed, rhythm, dynamic barking, loft.
Яковлева Наталья Борисовна

Преподаватель, Российский государственный университет физической культуры, спорта, молодёжи и туризма natascha.mouse@yandex.ru

яковлев Борис Александрович

К.n.н., дочент, Российский государственный университет физической культуры, спорта, молодёжи и туризма minigolf1@yandex.ru

Аннотация: Цель работы: определить особенности техники полного свинга гольфистами на этапе начальной подготовки. Для определения кинематических характеристик свинга использовался датчик Swing Talk. Определялась траектория головки клюшки, ее положение вовремя контакта с мячом, положение клюшки во время контакта с мячом. В эксперименте приняли участие 12 начинающих гольфистов в возрасте от 8 до 11 лет. Полный свинг выполнялся клюшкой айрон №8. Выявлены особенности выполнения полного свинга в зависимости от возраста и продолжительности обучения начинающих гольфистов.

Ключевые слова: свинг, кинематика свинга, скорость головки клюшки, ритм, динамический лай, лофт.

параметров производилась с помощью датчика Swing Talk фирмы Golfzon. Датчик массой 10,7 грамм устанавливался на грипп паттера. Передача данных с датчика осуществлялась с помощью соединения Bluetooth c планшетом (IPAD). Данное устройство позволяло регистрировать около тридцати различных кинематических параметров полного свинга. В исследовании анализировалась только часть из этих показателей; скорость головки клюшки, ритм, динамический лофт, динамический лай, наклон шафта относительно вертикали, время затраченное на прохождение головки клюшки при махе от начала движения до горизонтального положения исходя из того, что время от начала маха до контакта с мячом принято за 1, угол открытия (закрытия) клюшки, угол между вектором скорости головки клюшки и лицевой поверхностью, угол направления движения головки клюшки относительно линии прицеливания, угол атаки (угол приближения головки клюшки к мячу относительно горизонтальной поверхности, разность между плоскостью замаха и плоскостью маха свинга, плоскость замаха, плоскость маха, наклон шафта относительно вертикали. Знаки «+» или «-» означали соответственно закрыта или открыта головка клюшки, направление клюшки относительно линии прицеливания в момент контакта с мячом, смещение шафта относительно вертикали назад или вперед.

Полученные в ходе эксперимента данные позволи- 
ли выявить особенности техники выполнения полного свинга спортсменами на начальном этапе подготовки, а также изменение показателей техники свинга в зависимости от возраста спортсменов. Учитывая существенные изменения физиологических показателей организма юношей в возрасте от восьми до одиннадцати лет, испытуемые были разделены на две группы. Первую группу составляли спортсмены от восьми до девяти лет, вторая от десяти до одиннадцати. Каждая группа состояла из шести человек. В среднем во второй группе спортсмены осваивали технику полного свинга на 1,2 года дольше, чем спортсмены первой группы.

В результате исследования получены следующие кинематические показатели полного свинга (таблица 1).

Знаки «+» или «-» означали соответственно закрыта или открыта головка клюшки, направление клюшки относительно линии прицеливания в момент контакта с мячом, смещение шафта относительно вертикали назад или вперед.

Не выявлено достоверных различий среднеарифметических в группах следующих показателей: ритм, угол открытия (закрытия) клюшки, угол атаки (угол приближения головки клюшки к мячу относительно горизонтальной поверхности, разность между плоскостью замаха и пло- скостью маха свинга, плоскость замаха и плоскость маха.

Существенные различия между кинематическими показателями у спортсменов различных групп выявлены в скорости головки клюшки (16,6 и 27,41 м/с) во время контакта с мячом. Это объясняется большим возрастом и, как следствие, физически более развитыми спортсменами старшей группы.

Динамический лофт у спортсменов 8 - 9 лет гораздо больше, чем у спортсменов 10 - 11 лет (42,66 и 15,96 градусов соответственно). По-видимому, это происходит из-за ошибок в технике выполнения свинга. Спортсмены 8 - 9 лет стараются «поднять мяч» за счет «сильного удара», при этом возникает обратный эффект, из-за жесткого хвата динамический лофт клюшки увеличивается, в то время как спортсмены 10 - 11 лет выполняют свинг более технично. Больший угол лай у спортсменов 8 - 9 лет, чем у спортсменов 10 - 11 лет обусловлен ростом спортсменов и длиной клюшки. Чем больше длина клюшки, тем меньше угол лай. Вектор скорости головки клюшки у первой группы при контакте с мячом больше, чем у второй группы направлен внутрь (12,2 и 1,13 градусов соответственно).

В таблице 2 приведены значения коэффициентов корреляции между различными кинематическими пока-

Таблица 1.

Кинематические показатели полного свинга

\begin{tabular}{|c|c|c|c|c|c|c|c|c|c|c|c|c|c|}
\hline \multirow{2}{*}{$\begin{array}{c}\text { Возраст } \\
8-9 \text { (лет) }\end{array}$} & \multicolumn{13}{|c|}{ Кинематические показатели } \\
\hline & 1 & 2 & 3 & 4 & 5 & 6 & 7 & 8 & 9 & 10 & 11 & 12 & 13 \\
\hline сред. арифм. & 16,6 & 2,95 & 42,66 & 53,0 & $-4,42$ & 0,61 & $-1,43$ & 11,71 & $-12,2$ & $-8,4$ & $-6,4$ & 55,38 & 52,5 \\
\hline Станд. отклон. & 5,89 & 1,29 & 10,79 & 11,72 & 9,83 & 0,2 & 17,7 & 20 & 16 & 8,43 & 16,79 & 15,49 & 11,34 \\
\hline \multirow{2}{*}{$\begin{array}{c}\text { Возраст } \\
10-11 \text { (лет) }\end{array}$} & \multicolumn{13}{|c|}{ Кинематические показатели } \\
\hline & 1 & 2 & 3 & 4 & 5 & 6 & 7 & 8 & 9 & 10 & 11 & 12 & 13 \\
\hline сред. арифм. & 27,41 & 2,59 & 15,96 & 45,96 & $-17,98$ & 0,81 & $-12,1$ & $-6,02$ & $-1,13$ & $-12,9$ & $-13,75$ & 54,84 & 50,72 \\
\hline Станд. отклон. & 5,33 & 0,34 & 17,07 & 8,59 & 10,16 & 0,06 & 32,96 & 18,28 & 14,91 & 12,60 & 21,38 & 13,54 & 11,98 \\
\hline
\end{tabular}

1. скорость головки клюшки;

2. ритм;

3. динамический лофт;

4. динамический лай;

5. наклон шафта относительно вертикали;

6. время, затраченное на прохождение головки клюшки при махе от начала движения до горизонтального положения исходя из того, что время он начала маха до контакта с мячом принято за 1;

7. угол открытия (закрытия) клюшки;

8. угол между вектором скорости головки клюшки и лицевой поверхностью;

9. угол направления движения головки клюшки относительно линии прицеливания;

10. угол атаки (угол приближения головки клюшки к мячу относительно горизонтальной поверхности;

11. разность между плоскостью замаха и плоскостью маха свинга;

12. плоскость замаха,

13. плоскость маха. 
Таблица 2.

Значения коэффициентов корреляции между различными кинематическими показателями у спортсменов 8 - 9 лет *

\begin{tabular}{|c|c|c|c|c|c|c|c|c|c|c|c|c|c|}
\hline Показатели & 1 & 2 & 3 & 4 & 5 & 6 & 7 & 8 & 9 & 10 & 11 & 12 & 13 \\
\hline 1 & & & $-0,35$ & & $-0,62$ & 0,77 & & $-0,41$ & 0,58 & & & & \\
\hline 2 & & & & $-0,4$ & & $-0,45$ & & & & & & & $-0,49$ \\
\hline 3 & $-0,35$ & & & & 0,53 & & & 0,39 & $-0,42$ & & & & \\
\hline 4 & & $-0,4$ & & & & $-0,35$ & 0,71 & 0,68 & & & & & \\
\hline 5 & $-0,62$ & & 0,53 & & & $-0,46$ & & & $-0,8$ & & & & \\
\hline 6 & 0,77 & $-0,45$ & & $-0,34$ & $-0,46$ & & & & & & & 0,42 & \\
\hline 7 & & & & 0,71 & & & & 0,59 & & & & & \\
\hline 8 & $-0,41$ & & 0,39 & 0,68 & & & 0,59 & & & & & & 0,36 \\
\hline 9 & 0,58 & & $-0,42$ & & $-0,8$ & & & $-0,52$ & & 0,36 & & & \\
\hline 10 & & & & & & & & & 0,36 & & & 0,35 & \\
\hline 11 & & & & & & & & & & & & $-0,58$ & \\
\hline 12 & & & & & & 0,42 & & & & 0,35 & $-0,58$ & & 0,68 \\
\hline 13 & & $-0,49$ & & & & & & 0,36 & & & & 0,68 & \\
\hline
\end{tabular}

Таблица 3.

Значения коэффициентов корреляции между различными кинематическими показателями у спортсменов 10 - 11 лет*.

\begin{tabular}{|c|c|c|c|c|c|c|c|c|c|c|c|c|c|}
\hline Показатели & 1 & 2 & 3 & 4 & 5 & 6 & 7 & 8 & 9 & 10 & 11 & 12 & 13 \\
\hline 1 & & & & & & & & & & $-0,44$ & & & \\
\hline 2 & & & & & & & & & $-0,36$ & $-0,41$ & & 0,44 & \\
\hline 3 & & & & 0,57 & 0,72 & $-0,52$ & & 0,71 & $-0,61$ & $-0,36$ & & 0,36 & 0,45 \\
\hline 4 & & & & & & & & 0,56 & & & & & 0,47 \\
\hline 5 & & & 0,72 & & & 0,43 & & & $-0,62$ & & & & \\
\hline 6 & 0,57 & & $-0,52$ & & $-0,43$ & & & & & & & & $-0,41$ \\
\hline 7 & & & & & & & & & & & & & \\
\hline 8 & & & 0,71 & 0,56 & & & & & $-0,75$ & $-0,62$ & & 0,52 & 0,42 \\
\hline 9 & & $-0,36$ & $-0,61$ & & $-0,62$ & & & $-0,75$ & & 0,6 & 0,37 & $-0,39$ & \\
\hline 10 & $-0,44$ & $-0,41$ & $-0,36$ & & & & & $-0,62$ & 0,6 & & 0,36 & $-0,42$ & \\
\hline 11 & & & & & & & & & 0,37 & 0,36 & & $-0,38$ & 0,38 \\
\hline 12 & & 0,44 & 0,36 & & & & & 0,52 & $-0,39$ & $-0,42$ & $-0,38$ & & \\
\hline 13 & & &
\end{tabular}

зателями у спортсменов 8 - 9 лет.

У спортсменов 8 - 9 лет установлена высокая положительная взаимосвязь между временем, затраченным на прохождение головки клюшки при махе от начала движения до горизонтального положения исходя из того, что время он начала маха до контакта с мячом принято за 1 и скоростью головки клюшки $(0,77)$ 0,57, динамическим лаем и открытием головки клюшки во время контакта с мячом $(0,71)$. Высокая отрицательная взаимосвязь выявлена между наклоном шафта относительно вертикали и углом направления движения головки клюшки относительно линии прицеливания (-0,8) -0,62.
В таблице 3 приведены значения коэффициентов корреляции между различными кинематическими показателями у спортсменов 10 - 11 лет.

В результате анализа полученных данных спортсменов 10 - 11 лет установлена высокая положительная взаимосвязь между динамическим лофтом и наклоном шафта относительно вертикали в момент контакта головки клюшки с мячом $(0,72)(0,53)$, между динамическим лофтом и углом вектора скорости головки клюшки и лицевой поверхностью $(0,71)$ 0,39 и высокая отрицательная взаимосвязь между углом вектора скорости головки клюшки и углом направления движения головки клюш- 
ки относительно линии прицеливания $(-0,75)$.

Взаимосвязь между показателями имеет различную величину у спортсменов различного возраста, так если в первой группе высокая положительная взаимосвязь между временем, затраченным на прохождение головки клюшки при махе от начала движения до горизонтального положения исходя из того, что время он начала маха до контакта с мячом принято за 1 и скоростью головки клюшки 0,77, то во второй она равна 0,57. Тоже выявлено и между показателями наклоном шафта относительно вертикали и углом направления движения головки клюшки относительно линии прицеливания -0,8 и -0,62 во второй группе. Взаимосвязь между динамическим лофтом и наклоном шафта относительно вертикали в момент контакта головки клюшки с мячом во второй группе была высокой 0,72, то взаимосвязь между теми же показателями в первой группе была средней 0,53, аналогично, как и между динамическим лофтом и углом вектора скорости головки клюшки и лицевой поверхностью 0,71 и 0,39 соответственно.

\section{Зак^ючение}

В результате проведенных исследований выявлены различия значений кинематических показателей у спортсменов различных возрастов гольфистов на этапе начальной подготовки. Статистически достоверно отличаются такие величины кинематических показателей техники выполнения полного свинга как динамический лофт, динамический лай, вектор скорости головки клюшки.

Взаимосвязи между отдельными показателями в различных группах имеют различную силу. Выявлено, что высокая взаимосвязь между некоторыми признаками в одной группе может быть слабой в другой группе.

\section{ЛИТЕРАТУРА}

1. Учебная программа по предмету «физическая культура» для общеобразовательных учреждений на основе вида спорта - гольф. - Электронный ресурс . URL: https://olimpiec-nn.ru/File/before_2019/GOLF.pdf (дата обращения: 12.02.2021)

2. Golf Champions Электронный ресурc. URL: https://ok.ru/golfchampi/topic/68946030687691 (дата обращения: 2.01.2021)

3. Johnson S.H., and Lieberman B.B. (1994) An analytical model for ball-barrier impact, part 2, a model for oblique impact, in: Science and Golf II, Proceedings of the Second World Scientific Congress of Golf,A. J. Cochran and M.R. Farrally, eds., E \& F.N. Spon, London, pp. 315-320.

4. Patricia M. Donnelly (2003) Teaching and Sustaining the Child Player Educational Sport Psychologist. Weston, Connecticut, $134 \mathrm{p}$.

5. Rees-Jones J. (2002) A spatial model of the rigid body club swing, in: Science and Golf IV, Proceedings of the Fourth World Scientific Congress of Golf, E. Thain, ed., Routledge, pp. 3-12.

6. Serandour (2001) The application of the oblique impact of an elastic sphere theory to the study of the golf ball behaviour, Project report for Diplôme d'Ingéur de I'Institut National des Sciencess Appliquées de Toulouse.

7. Turner A.B., Hills N.J. (1999) A three-link mathematical model of the golf swing, in: Science and Golf III, Proceedings of the Third World Scientific Congress of Golf, M. R. Farrally, and A.J. Cochran, eds., Human Kinetics, pp. 3-12.

8. Wesson John (2011) The Science of Golf. Oxford: Oxford University Press. 288 р. Электронный ресурc .URL: https://books.google.ru/books?id=hZzEs2Ps7EMC\&pri $n t s e c=$ frontcover\&hl=ru\&source=gbs_ge_summary_r\&cad=0\#v=0nepage\&q\&f=false (дата обращения: 12.02.2021). 